\title{
Lignin and Ethylcellulose in Controlled Release Formulations to Reduce Leaching of Chloridazon and Metribuzin in Light-Textured
} Soils

F. FLORES-CÉSPEDES ${ }^{\mathrm{a}}$, I. DAZA-FERNÁNDEZ ${ }^{\mathrm{a}}$, M. VILLAFRANCA-SÁNCHEZ M. FERNÁNDEZ-PÉREZ ${ }^{a^{*}}$, E. MORILLO ${ }^{\mathrm{b}}$, T. UNDABEYTIA ${ }^{\mathrm{b}}$

${ }^{\mathrm{a}}$ Department of Chemistry and Physics, Research Centre CIAIMBITAL, University of Almería, Agrifood Campus of International Excellence (ceiA3), Crta. Sacramento s/n, 04120 Almería, Spain

${ }^{\mathrm{b}}$ Instituto de Recursos Naturales y Agrobiología de Sevilla (IRNAS-CSIC) Av. Reina Mercedes, 10. E-41012 Sevilla, Spain

E-mail address of the authors: F. Flores-Céspedes: frflores@ual.es; I. Daza-Fernández: idf482@ual.es; M. Villafranca-Sánchez: villafra@ual.es; E. Morillo: morillo@irnase.csic.es; T. Undabeytia: undabeyt@irnase.csic.es M. Fernández-Pérez: mfernand@ual.es

\footnotetext{
* Address correspondence to Manuel Fernández-Pérez, Department of Chemistry and Physics, University of Almería, Ctra. Sacramento s/n, 04120, Almería (Spain); Phone: 34950 015961, Fax: 34950 015008, E-mail: mfernand@ual.es
} 


\section{Highlights}

The use of CRFs reduces the presence of chloridazon and metribuzin in the leachate

CRFs coated with EC and DBS provides the lowest percentages of herbicides leached

The use of CRFs leads to increase the herbicide effectiveness in soil

A correlation between herbicide recovered in leachates and $T_{50}$ values was obtained 


\begin{abstract}
In this research, controlled release formulations (CRFs) of the herbicides chloridazon and metribuzin, identified as potential leachers, have been evaluated in soils with different texture. To prepare the CRFs, ethylcellulose (EC) and dibutylsebacate (DBS) have been used as coating agents in lignin-polyethylene glycol based formulations.
\end{abstract}

Mobility experiments have been carried out in two light textured soils (sandy and sandy-loam). Breakthrough curves have shown that the use of CRFs reduces the presence of chloridazon and metribuzin in the leachate compared to technical and commercial products, being the lignin CRF coated with EC and DBS the most efficient to diminish the herbicide leaching.

Mass balance study has shown a higher amount of chloridazon and metribuzin recovered in soils when these herbicides were tested as CRFs compared to technical and commercial products. The gradual release of herbicides from the CRFs resulting in a rather available levels of chloridazon and metribuzin in soil for a longer time. A good correlation between percentages of herbicide recovered in leachates and $T_{50}$ values (time corresponding to $50 \%$ release of herbicide in water) was obtained, which allows to select the most appropriate $\mathrm{CRF}$ in each agro-environmental practice to reduce the potential pollution of groundwater by chloridazon and metribuzin.

Keywords: Herbicides; Lignin; Ethylcellulose; Controlled release; Leaching. 


\section{INTRODUCTION}

Nowadays the use of large amount of herbicides for the control of weeds in crops represents a major challenge to maintain welfare. The proper use of these chemicals can contribute to protect natural resources and to avoid environmental pollution and damage on the public health [1].

Different fates have been observed when herbicides are applied in the field. Among others, uptake by plants, degradation process, movement, out-target, immobilization and unintentional discharge in the environment. Effectively control weeds with few or no adverse environmental must be observed in a well-planned management system. However, the high amount of herbicides used in agronomic practices leads to the existence of contaminated groundwater sources, mainly through the leaching process [2-4]. The most important parameters that determine herbicide capacity to leach, and so capable to reach groundwater, are the herbicide properties, being persistence in soil and sorption the most relevant ones. To calculate the leaching potential of a substance, the Groundwater Ubiquity Score (GUS) can be used. This index can be calculated from its organic carbon normalized sorption coefficient $\left(K_{\mathrm{oc}}\right)$ and the parameter of soil persistence halftime $\left(\mathrm{DT}_{50}\right)$ by the next equation [5]:

$$
\text { GUS }=\log \left(\mathrm{DT}_{50}\right) \times\left(4-\log \left(K_{\mathrm{oc}}\right)\right)
$$

According to GUS index, the herbicides chloridazon and metribuzin (2.78 and 2.57 , respectively) have been identified as potential leachers [6].

Chloridazon (5-amino-4-chloro-2-phenylpyridazin-3(2H)-one), which is used as a selective systemic herbicide that inhibits photosynthesis and is used for the general 
control of weeds [7]. The herbicide chloridazon is considered as a mobile molecule in some soils despite the existence of contradictory results. The $\mathrm{K}_{\mathrm{oc}}$ values for chloridazon ranged from 89 to 340 according to several investigations [8]. These $\mathrm{K}_{\mathrm{oc}}$ values shows that this herbicide could have an important tendency to leach in soils, in agreement to the Cohen classification [9].

Metribuzin, 4-amino-3-methylthio-6-ter-butyl-1,2,4-triazin-5(4H)-one, is a selective systemic herbicide, being well absorbed both by root and foliar routes with translocation to all plants parts. This herbicide is used for the control of annual broadleaf weeds in field crops and vegetables. The herbicide metribuzin is a very soluble compound in water (water solubility $=1050 \mathrm{mg} \mathrm{L}^{-1}$ at $20{ }^{\circ} \mathrm{C}$ ) and therefore tends to adsorb little in most soils [10].

The development of CRFs based on polymeric materials for its use in agriculture will allow to apply highly soluble herbicides such as chloridazon and metribuzin in an efficient way and with a minimum pollution risk resulting from rapid runoff and leaching. Controlled-release technology of agrochemicals is based on the use of existing active ingredients and selected natural materials. The aim of this technique is to develop formulations that allows the precise and quantitative release of the active ingredients, and finally to achieve the most economic, safe and effective control of pests and weeds and reducing the environmental contamination $[11,12]$. Encapsulation of agrochemicals into polymeric carriers has attracted emerging interests. The polymeric matrix prevents direct exposure of the active ingredient to environment, reducing loss of degradation and evaporation [13-15]. 
The nature and type of polymeric material are the parameters that affect the properties of controlled release formulations. Different polymers have been used in the preparation of controlled release systems. Natural polymers such as alginate, lignin, starch, ethylcellulose, chitosan and so on, have been preferably used instead synthetic polymers due to their biodegradability characteristics, low cost, free availability, and non-toxicity [14, 16-19].

One of the polymers widely used in CRFs synthesis is the lignin, a low-cost waste product in the paper pulp manufacturing process, which is readily available, cheap and a currently underutilized resource [20-22]. Several encapsulation methods and different agrochemicals have been used to obtain lignin-based controlled release systems. Polyethylene glycol (PEG) and ethylcellulose (EC) have been used to optimize lignin-based formulations prepared with highly water soluble herbicides, such as chloridazon and metribuzin, and increase their release efficiency [18, 23]. These previous papers were focused on synthesis, characterization and evaluation in water of the controlled release systems.

In this paper, we investigate the potential use of these CRFs to control the release and leaching behaviour of both herbicides in soils. These studies could lead to obtain a higher knowledge of herbicides behavior as leacher in soils when there are uses as CRFs.

The purposes of this study were to evaluate the capacity of the CRFs based on lignin to control release rate and leaching of metribuzin and chloridazon in soils. The mobility of herbicides from CRFs was compared to those of technical grade and 
commercial products in soil column experiments. Furthermore, the influence of physico-chemical properties of two soils on the herbicides distribution from CRFs, technical grade and commercial products has been also researched.

\section{MATERIALS AND METHODS}

\subsection{Chemicals and soils}

Metribuzin (93.0\%) and chloridazon (93.5\%) technical grade (TG) were nicely provided by Industrias Afrasa, S. A. (Valencia, Spain). Their molecular formula and selected properties are as follows [6]. For metribuzin, molecular formula: $\mathrm{C}_{8} \mathrm{H}_{14} \mathrm{~N}_{4} \mathrm{OS}$; water solubility $\left(20{ }^{\circ} \mathrm{C}\right): 1165 \mathrm{mg} \mathrm{L}^{-1}$; octanol/water partition coefficient $\left(\log \mathrm{K}_{\mathrm{ow}}\right)(20$ $\left.{ }^{\circ} \mathrm{C}\right)$, 1.60. For chloridazon, molecular formula: $\mathrm{C}_{10} \mathrm{H}_{8} \mathrm{ClN}_{3} \mathrm{O}$; water solubility $\left(20{ }^{\circ} \mathrm{C}\right)$ : $422 \mathrm{mg} \mathrm{L}^{-1}$; octanol/water partition coefficient $\left(\log \mathrm{K}_{\mathrm{ow}}\right)\left(20^{\circ} \mathrm{C}\right), 1.19$.

Commercial formulation of chloridazon $(65 \%)$ in the form of water-dispersible granules (Pyramin DF) was supplied by BASF Crop Protection (Barcelona, Spain). Commercial formulation of metribuzin (70\%), in the form of water-dispersible granules (Eclipse 70 WG) was supplied by Makhteshim Agan España S.A. (Valencia, Spain).

Indulin AT commercially available pine kraft lignin, used for CRFs preparation, was kindly supplied by Westvaco Corp., Charleston, SC. Polyethylene glycol with a molecular weight of $1000 \mathrm{~g} \mathrm{~mol}^{-1}$ was used to improve the formulation homogeneity; ethylcellulose (Ethocel ${ }^{\circledR}$; ethoxy content, 48.0-49.5\%; viscosity, 9-11 cp) was used as film-forming material of polymer coating ; and finally, dibutylsebacate, (DBS), ( $\geq 97$ $\%, \mathrm{~d}=0,936 \mathrm{~g} \mathrm{~mL}^{-1}$ ) was selected as plasticizer. These chemical were provided by Fluka Chemie AG (Buchs, Switzerland). 
Acetonitrile (HPLC grade) and demineralized water (milli-Q quality) from Sigma Chemical Co. (St. Louis, USA) were used as solvents for HPLC determinations. . For metribuzin HPLC analysis, potassium di-hydrogen phosphate $(99.5 \%)$ from Panreac S.A. (Barcelona, Spain), was used also in the mobile phase.

Two soils from Andalucía region were used in this study. Soil 1, which is representative soil of the zone of "Campo de Dalías" (Almería, south-eastern of Spain), was a calcareous soil and has a sandy-loam texture. Surface layer $(0-20 \mathrm{~cm})$ (U.T.M.: $\mathrm{x}=526.100 ; \mathrm{y}=4071.700)$ of soil 1 was sampled. . Soil 2 , located at the CSIC experimental land 'La Hampa' (Seville, south of Spain) (U.T.M.: x=759982.42; $\mathrm{y}=41305.57)$, presented a sandy texture. Using standard methods air-dried $<2-\mathrm{mm}$ particle size samples were analyzed. A glass electrode method [24] was used to determine the soil pH.; the Walkley-Black method [25] and the hydrometer method [26] were used to determine organic matter content and clay content respectively. Table 1 shows the above mentioned properties.

\subsection{Preparation of CRFs}

The lignin-PEG based CRFs were formed using a similar method to that proposed by Fernández-Pérez et al. $[18,23]$. The non-coated CR granules were obtained by mixing lignin, polyethylene glycol and active ingredient in the optimized ratio [65: 20: $15(\mathrm{w} / \mathrm{w})$ ] $[18,23]$. Under melting conditions (at $126^{\circ} \mathrm{C}$ and $206^{\circ} \mathrm{C}$ during $20 \mathrm{~min}$ for metribuzin and chloridazon, respectively) the mixtures were heated and stirred. Then, lignin-PEG glassy matrixes were cooled and crushed in a grinder. Finally, particles with size ranged from 0.2 $\mathrm{mm}$ to $1 \mathrm{~mm}$ were obtained by sieving. The prepared formulations are named in the 
manuscript as CPEL for CR formulation containing chloridazon (C) and MPEL for CR formulation containing metribuzin (M).

To obtain ethylcellulose coated formulations, non-coated CR formulation (20 g) were located into a fluidized-bed coater (Mini-Glatt, Glatt AG, Pratteln 1, Switzerland) assembled with a Wurster insert. The temperature was set to $60{ }^{\circ} \mathrm{C}$ for formulations containing chloridazon and $40{ }^{\circ} \mathrm{C}$ for metribuzin granules. The coating membrane consists of $10 \%$ and $20 \%$ ethylcellulose related to the weight of the dry granules $(20 \mathrm{~g})$. Plasticizer coating solution have a $20 \%$ and $2.25 \%$ of EC and DBS, respectively, as described in previous papers by the authors $[18,23]$. The active ingredient percentage of chloridazon and metribuzin in lignin-PEG based CRFs and ethylcellulose coated ligninbased CRFs are shown in Table 2, together with the values of encapsulation efficiency (EE).

\subsection{Herbicide Analysis}

High-performance liquid chromatography (HPLC) was used to determine chloridazon and metribuzin concentrations. Analysis was conducted with a System Gold HPLC equipped with a solvent delivery module, model 126, diode-array detector, model 168 and 32 Karat data station from Beckman Coulter Inc, (Fullerton, CA, USA). The HPLC operating conditions to analyze chloridazon and metribuzin were described previously by the authors $[7,14,18]$.

\subsection{Herbicide Mobility in Soils}


Metacrylate pipe $(3.0 \mathrm{~cm}$ internal diameter, $20 \mathrm{~cm}$ length) was used to prepare the columns [27]. To avoid displacement of the soil and minimize the dead-end volume, nylon mesh (pore diameter of $60 \mu \mathrm{m}$ ) and a layer of wool-glass were sealed to the bottom of each column [28]. The columns were packaged with soil $(16 \mathrm{~cm})$ and washed acid sand at the top $(1 \mathrm{~cm})$. The columns were saturated with distilled water via capillarity and then were left to be drained for one day before the application of the chloridazon and metribuzin treatments. The resulting pore volume were of 40 and 50 $\mathrm{mL}$ for sandy-loam soil and sandy soil, respectively.

Chloridazon and metribuzin technical grade and their commercial products and lignin-PEG based CRFs) were supplied at a rate of $5 \mathrm{~kg}$ a.i. $\mathrm{ha}^{-1}$. These experiment were performed twice. Then, $25 \mathrm{~mL}$ of distilled water (equivalent to $35 \mathrm{~mm}$ of rain) was added to the column daily until complete 10 pore volumes for chloridazon and 8 pore volumes for metribuzin. These volumes correspond to the amount of water needed for $90 \%$ of active ingredient, applied as technical product, appears in the leachate. Aliquots from the leachates collected daily were analyzed by HPLC to determine herbicide concentration.

Once the leaching experiments were concluded, the content of chloridazon and metribuzin in soil and granules was calculated. For that, soil subsamples (10 g) were extracted with a methanol:water $(80: 20)$ mixture $(50 \mathrm{~mL})$ for $24 \mathrm{~h}$, and analyzed by HPLC.. The herbicide content in the granules was determined by extracting the granules (20 mg) with methanol $(50 \mathrm{~mL})$ using an ultrasonic bath for $15 \mathrm{~min}$. Then the volume was made up to $100 \mathrm{~mL}$ with water and the solution was shaken in a thermostated bath at 
$25 \pm 1 \mathrm{C}^{\circ}$ for $24 \mathrm{~h}$. The resulting extract was filtered using nylon filters $(0.20 \mu \mathrm{m})$ and analyzed by HPLC.

The mass balance was calculated at the end of all experiments of mobility of herbicides in soil.

\section{RESULTS AND DISCUSSION}

\subsection{Herbicide Mobility in Soils}

Figure 1 shows the breakthrough curves from soil columns treated with chloridazon and metribuzin. The data of leaching process have been represented in the form of active ingredient in the leachate expressed as $\mathrm{mg} \mathrm{L}^{-1}$ versus the number of pore volumes. Together with the active ingredient curves from the CRFs, the data corresponding to technical and commercial products are also shown in order to establish a comparison between these curves.

Differentiated behaviors were noted in the leaching patterns of the products researched. Breakthrough curves obtained with technical products and commercial formulations showed in general a uniform behavior. The active ingredients were first spotted in the leachate at approximately 1.0 pore volume, increasing the amount present in each leachate fraction quickly up to a maximum, at approximately 2.0 pore volume, then decreasing also fastly. Similar behaviors have been observed for chloridazon and metribuzin breakthrough curves achieved in soils by other authors [14, 29, 30].

When herbicides were applied as controlled-release formulations, a delay in the appearance of active ingredient in the breakthrough curves was observed, being necessary 
approximately 2.0 pore volume for the emergence of metribuzin and chloridazon in the leachate. On the other hand, the leaching curves showed their maximums displaced to the right in relation to the maxima of the curves corresponding to the technical products as well as to the commercial ones, being in general also these maxima less accentuated.

A smoother slope in lignin-PEG based CRFs curves was appreciated compared to those obtained for technical and commercial products, mainly for formulations coated with ethylcellulose. A higher residence of chloridazon and metribuzin in soil columns and so a higher efficacy and less leaching potential of these herbicides can be inferred from the retard and the smoother slope observed in the breakthrough curves.

The cumulative leaching curves are shown in Figure 2. These curves showed a clearly differentiated pattern when herbicides are applied as technical and commercial products or as CRFs. For both technical and commercial metribuzin, four pore volumes were necessary to leach the $90 \%$ of the total herbicide initially applied in the tested soils (Fig $2 \mathrm{a}$ and 2c). For CRFs prepared with metribuzin (Fig 2a and 2c), a smoother lixiviation profile was appreciated, which means that the use of CRFs reduces leaching of metribuzin in a very acceptable level during the whole experiment compared to technical and commercial products. For chloridazon (Fig. 2b and 2d), 90\% of the technical and commercial product was leached in approximately 7 pore volumes while only a maximum of $50 \%$ and $70 \%$ of herbicide were leached from CRFs at these pore volume in sandy soil and in sandy-loam soil, respectively. The lower water solubility of chloridazon in relation to metribuzin can explain the above obtained results. Thus, both the weak control over the release of metribuzin from lignin-based CRFs and the quick 
dissolution in water of this herbicide cause a faster process of leaching in soil of metribuzin compared to chloridazon.

Considering only the behavior of CRFs, the lowest percentages of herbicide recovered in the leachate were observed in the CRFs coated with ethylcellulose and plasticizer $\left(\mathrm{CPEL}+\mathrm{EC}_{20}+\mathrm{DBS}\right.$ and $\left.\mathrm{MPEL}+\mathrm{EC}_{20}+\mathrm{DBS}\right)$. Besides, as expected, the highest quantity of $\mathrm{EC}$ in $\mathrm{CPEL}+\mathrm{EC}_{20}$ and $\mathrm{MPEL}+\mathrm{EC}_{20}$ formulations compared to $\mathrm{CPEL}+\mathrm{EC}_{10}$ and MPEL$+\mathrm{EC}_{10}$ caused a decrease in the amount of herbicide leached. This fact can be explained if we take into account that the diffusion of water through the CRFs coated with EC was slowed down as the thickness of the membrane increases. This behavior was also been observed when these CRFs formulations were tested in water $[18,23]$.

\subsection{Herbicide mass balance}

Figure 3 shows the percentages of herbicides chloridazon and metribuzin recovered in soil, granules and leachate in relation to the whole herbicide applied.

As it was indicated above, the percentages of active ingredient recovered in the leachate was closely related to the type of formulation applied in the soil columns, following the next order:

$\mathrm{TG}$ product $\approx$ Commercial formulation $>\mathrm{CPEL}>\mathrm{CPEL}+\mathrm{EC}_{10}>\mathrm{CPEL}+\mathrm{EC}_{20}>$ $\mathrm{CPEL}+\mathrm{EC}_{20}+\mathrm{DBS}$ for chloridazon, and $\mathrm{TG}$ product $\approx$ Commercial formulation $>$ MPEL > $\mathrm{MPEL}+\mathrm{EC}_{10}>\mathrm{MPEL}+\mathrm{EC}_{20}>\mathrm{MPEL}+\mathrm{EC}_{20}+\mathrm{DBS}$ for metribuzin. 
Besides, a lower percentage of active ingredient in the leachate was obtained in the columns treated with chloridazon formulations compared to those tested with metribuzin formulations. These results are in agreement with the lower water solubility of chloridazon compared to metribuzin and the lower values of $K_{o w}$ and $K_{o c}$ of the metribuzin [6]. Besides, $\mathrm{T}_{50}$ values (the time taken for $50 \%$ of the active ingredient to be released from the CRFs into water) obtained for the CRFs prepared with metribuzin were lower than those obtained with chloridazon CRFs [18, 23].

Furthermore, for the CRFs tested a higher amount of active ingredient leached was observed in the columns prepared with the sandy-loam soil. This could be explained if we consider the lower permeability of sandy-loam soil compared to the sandy soil, which allows longer contact time of the water with the formulations, thus producing a greater dissolution of the active ingredient and therefore higher amounts of herbicide leached $[31,32]$.

In relation to the amount of herbicide recovered in the granules (sand washed layer), the percentage recovered ranged from 0 to $2.61 \%$ when chloridazon and metribuzin were applied as technical and commercial products. So, more than $97 \%$ of the active ingredient applied were mobilized. For CRFs the percentage of active ingredient recovered in the sand washed layer ranged from $1.77 \%$ for the CPEL formulation tested in the sandyloam soil and $64.36 \%$ for $\mathrm{CPEL}+\mathrm{EC}_{20}+\mathrm{DBS}$ formulation tested in the sandy soil. It was further noted that the appearance of the herbicides in the leachate was directly related to the values of $\mathrm{T}_{50}$ parameter obtained from the experiences of release in water (Table 2). 
A detailed study of percentages of herbicides recovered in CRFs granules has showed that the above cited results were in accordance with the $\mathrm{T}_{50}$ values obtained from the release kinetics study made in water (Table 2). Thus, lignin monolithic matrices (CPEL and MPEL), with lower $\mathrm{T}_{50}$ values, resulted in a less control in the release of the active ingredient in relation to the coated ethylcellulose formulations $\left(\mathrm{CPEL}+\mathrm{EC}_{10}, \mathrm{CPEL}+\mathrm{EC}_{20}\right.$, MPEL+EC 10 and MPEL+EC 20 ). The highest control on the release of the active ingredients was reached with the coated ethylcellulose and plasticizer formulations $\left(\mathrm{CPEL}+\mathrm{EC}_{20}+\mathrm{DBS}\right.$ and MPEL+EC $\left.20+\mathrm{DBS}\right)$. For coated CRFs, a higher percentage of chloridazon remained in granules compared to those prepared with metribuzin in agreement with the different value of solubility in water of these herbicides.

Furthermore, a higher amount of active ingredient recovered in granules was obtained in the columns prepared with the sandy soil. This can be explained, as above indicated, considering the lower water permeability of sandy-loam soil, which allows a longer contact time of water with CRFs and, therefore, a higher amount of a.i. dissolved compared to the sandy soil.

Finally, as can be seen in figure 3, higher percentages of chloridazon and metribuzin were recovered in the sandy-loam soil. This could be explained if we consider the higher organic matter content of this soil, which determines the amount of herbicide sorbed, being higher for the sandy-loam soil than for the sandy soil [33].

The lignin based CRFs researched generated a decreasing in the amount of chloridazon and metribuzin recovered in the leachates compare to other CRFs previously studied. The percentage of herbicide recovered in the leachate, using lignin CRFs, 
diminished over $15 \%$ for chloridazon and over $50 \%$ for metribuzin in relation to those CRFs previously prepared with alginate and sorbents [34]. So, the results obtained in this study showed an improvement on prevention of herbicide pollution through the use of lignin based CRFs.

As commented above, it seems that the $\mathrm{T}_{50}$ value obtained in water is the most influential factor that affects the amount of herbicide recovered in leachate. So, $\mathrm{T}_{50}$ values of lignin based CRFs (Table 2) were related to the overall amount, given in percentage, of chloridazon or metribuzin recovered in the leachates (CRL or MRL). Figure 4 shows the plot of the $\mathrm{T}_{50}$ values for chloridazon and metribuzin versus the percentage of herbicide recovered in the leachate for each $\mathrm{CRF}$ tested in sandy-loam and sandy soils. The analysis indicates that $T_{50}$ values are well-correlated with the overall amount leached. The equations of linear correlation and correlation coefficients were obtained by applying the minimum-squares method to the data.

$$
\begin{array}{lll}
\operatorname{MRL}(\%)=73.98-0.52 \mathrm{~T}_{50} & \mathrm{r}=0.939 & \mathrm{p}=0.061 \text { (sandy-loam soil) } \\
\operatorname{MRL}(\%)=74.34-1.27 \mathrm{~T}_{50} & \mathrm{r}=0.988 & \mathrm{p}=0.011 \text { (sandy soil) } \\
\operatorname{CRL}(\%)=75.02-0.62 \mathrm{~T}_{50} & \mathrm{r}=0.996 & \mathrm{p}=0.004 \text { (sandy-loam soil) } \\
\operatorname{CRL}(\%)=66.73-0.55 \mathrm{~T}_{50} & \mathrm{r}=0.964 & \mathrm{p}=0.035 \text { (sandy soil) }
\end{array}
$$

From the linear correlations obtained, the amount of herbicide leached in soil from the different CRFs could be easily predicted from the $T_{50}$ values obtained in their release experiments made in water. Using the values of MRL (\%) or CRL (\%), obtained from the equations $1-4$, it would be possible to predict the herbicide behavior as leacher in these kind of soils. This set of data can be used to select the most appropriate CRFs 
depending on the soil characteristics, mainly to avoid the chloridazon and metribuzin tendency to leach.

\section{CONCLUSIONS}

Mobility experiments carried out in soils have shown that the use of CRFs reduces the presence of chloridazon and metribuzin in the leachate compared to technical and commercial products. Besides, considering only the behavior of CRFs, the lowest percentages of herbicides leached have been obtained for lignin CRFs coated with ethylcellulose and DBS. For the CRFs tested, a lower amount of active ingredient leached was observed in the columns prepared with the sandy soil compared to those prepared with the sandy-loam soil.

The mass balance study have shown a higher amount of chloridazon and metribuzin recovered in soil when these herbicides were tested as CRFs compared to technical and commercial products. This fact leads to increase the effectiveness of these herbicides used as CRFs.

A good correlation between percentages of herbicide recovered in leachates and $T_{50}$ values was obtained. The equations derived from this study can be used to select the most appropriate $\mathrm{CR}$ formulation in each agro-environmental situation to reduce the potential pollution of groundwater by chloridazon and metribuzin.

\section{ACKNOWLEDGEMENTS}

We thank Industrias Afrasa, S. A. for samples of chloridazon and metribuzin. 
1

\section{FUNDING}

This work was supported by the Spanish Ministry of Economy and Competitiveness through the research project AGL2010-18286 and Junta de Andalucía Excellence Project P-06-FQM-1909, co-financed by FEDER. 


\section{REFERENCES}

[1] L. J Jr. Guilette, T. Igushi, Life in a contaminated world, Science. 337 (2012) 16141615.

[2] M.A. Khan, C. D. Brown, Influence of commercial formulation on leaching of four pesticides through soil, Sci. Total Environ. 573 (2016) 1573-1579,

[3] V. Hakoun, P. Orban, A. Dassargues, S. Brouyère, Factors controlling spatial and temporal patterns of multiple pesticide compounds in groundwater (Hesbaye chalk aquifer, Belgium), Environ. Pollut. 223 (2017) 185-199.

[4] A. Menchen, J. D. Heras, J. J. G. Alday, Pesticide contamination in groundwater bodies in the Júcar River European Union Pilot Basin (SE Spain), Environ. Monit. Assess. 189 (2017) 146.

[5] D. I. Gustafson, Groundwater Ubiquity Score: A simple method for assessing pesticide leachability, Environ. Toxicol. Chem. 8 (1989) 339-357.

[6] The Pesticide Properties Database developed by the Agriculture \& Environment Research Unit (AERU), University of Hertfordshire, funded by UK national sources and the EU-funded FOOTPRINT project (FP6-SSP-022704), 2017.

[7] F. Flores-Céspedes, M, Villafranca-Sánchez, S. Pérez-García, M. Fernández-Pérez, Modifying sorbents in controlled release formulations to prevent herbicides pollution, Chemosphere 69 (2007) 785-794. 
[8] C. Tomlin, The e-Pesticide Manual. $12^{\text {th }}$ ed. Version 2.2. BCPC, Hampshire. UK, 2002.

[9] S. Z. Cohen, 1990. Pesticides in groundwater: An overview, in: Hutson, D. H. and Roberts, T. R. (Eds), Environmental Fate of Pesticides. John Wiley and Sons: Chichester, NY. 1990, pp. 13-26.

[10] V. Pot, P. Benoit, M. L. Menn, T. Sveistrup, J. Kværner, Metribuzin transport in undisturbed soil cores under controlled water potential conditions: Experiments and modelling to evaluate the risk of leaching in a sandy loam soil profile, Pest Manag. Sci. 67 (2001) 397-407.

[11] F. Sopeña, C. Maqueda, E. Morillo, Controlled release formulations of herbicides based on micro-encapsulation, Cien. Inv. Agr. 35 (2009) 27-42.

[12] E. V. R. Campos, J. L. Oliveira, L. F. Fraceto, Applications of controlled release systems for fungicides, herbicides, acaricides, nutrients, and plant growth hormones: a review, Adv. Sci. Eng. Med. 6 (2014) 1-15.

[13] F. Sopeña, A. Cabrera, C. Maqueda, E. Morillo, Ethylcellulose formulations for controlled release of the herbicide alachlor in a sandy soil, J. Agric. Food Chem. 55 (2007) 8200-8205.

[14] M. Fernández-Pérez, M. Villafranca-Sánchez, F. Flores-Céspedes, S. PérezGarcía, I. Daza-Fernández, Prevention of chloridazon and metribuzin pollution using lignin-based formulations, Environ. Pollut. 158 (2010) 1412-1419. 
[15] J. Li, J. Yao, Y. Li, Y, Shao, Controlled release and retarded leaching of pesticides by encapsulating in carboxymethyl chitosan /bentonite composite gel, J. Environ. Sci. Health, Part B 47 (2012) 795-803.

[16] J. I. Pérez-Martínez, E. Morillo, C. Maqueda, J. M. Ginés, Ethylcellulose polymer microspheres for controlled release of norfluazon, Pest Manag. Sci. 57 (2001) 688-694.

[17] M. Fernández-Pérez, F. Flores-Céspedes, E. González-Pradas, M. VillafrancaSánchez, S. Pérez-García, F. J. Garrido-Herrera, Use of activated bentonites in controlled release formulations of atrazine, J. Agric. Food Chem. 52 (2004) 38883893.

[18] M. Fernández-Pérez, M. Villafranca-Sánchez, F. Flores-Céspedes, I. DazaFernández, Ethylcellulose and lignin as bearer polymers in controlled release formulations of chloridazon, Carbohydr. Polym. 83 (2001) 1672-1679.

[19] T. Sánchez-Verdejo, T. Undabeytia, S. Nir, C. Maqueda, E. Morillo, Environmentally friendly slow release formulations of alachlor based on clayphosphatidylcholine, Environ. Sci. Technol. 42 (2008) 5779-5784.

[20] J. V. Cotteril, R. M. Wilkins, Controlled release of phenylurea herbicides from a lignin matrix: Release kinetics and modification with urea. J. Agric. Food Chem. 44 (1996) 2908-2912. 
[21] M. Fernández-Pérez, E. González-Pradas, M. D. Ureña-Amate, R. Wilkins, I. Lindup, Controlled release of imidacloprid from a lignin matrix: water release and mobility study, J. Agric. Food Chem. 46 (1998) 3828-3834.

[22] F. J. Garrido-Herrera, I. Daza-Fernández, E. González-Pradas, M FernándezPérez, Lignin-based formulations to prevent pesticides pollution, J. Hazard. Mater. 168 (2009) 220-225.

[23] M. Fernández-Pérez, M. Villafranca-Sánchez, F. Flores-Céspedes, I. DazaFernández, Lignin-Polyethylene glycol matrices and ethylcellulose to encapsulate highly soluble herbicides, J. Appl. Polym. Sci. 132 (2015) 41422.

[24] M.L. Jackson, Análisis Químico de Suelos, Omega, Barcelona, 1982.

[25] A. Walkley, I. A. Black, An examination of the degtjareff method for determining soil organic matter, and a proposed modification of the chromic acid titration method, Soil Sci. 37(1934) 29-38.

[26] G.J. Bouyoucos, Directions for making mechanical analysis of soils by the hydrometer method, Soil Sci. 4, (1936) 225-228.

[27] F. Flores-Céspedes, I. Daza-Fernández, M. Villafranca-Sánchez, M. FernándezPérez, Use of ethylcellulose to control chlorsulfuron leaching in a calcareous soil, J. Agric. Food Chem. 57 (2009) 2856-2861. 
[28] G. F. Fleming, W. Simmons, L. M. Wax, R. E. Wing, M.E. Carr, Atrazine movement in soil columns as influenced by starch-encapsulation. Weed Sci. 40 (1992) 465-470.

[29] R. M. Johnson, A. B. Pepperman, Soil column mobility of metribuzin from alginate-encapsulated controlled release formulations, J. Agric. Food Chem., 43 (1995) 241-246.

[30] T. Undabeytia, E. Recio, C. Maqueda, E. Morillo, E. Gómez-Pantoja, T. Sánchez-Verdejo, Reduced metribuzin pollution with phosphatidylcholine-clay formulations, Pest Manag. Sci. 67 (2011) 271-278.

[31] M. Abu-Zreig, R. P. Rudra, Modeling of atrazine transport in the presence of surfactants, J. Environ. Sci. Health Part B-Pestic. Contam. Agric. Wastes 37 (2002) $15-32$.

[32] C. Leu, H. Singer, C. Stamm, S. R. Müller, R. P. Schwarzenbach, Variability of herbicide losses from 13 fields to surface water within a small catchment after a controlled herbicide application, Environ. Sci. Technol. 38 (2004) 3835-3841.

[33] C. Maqueda, J. Villaverde, F. Sopeña, T. Undabeytia, E. Morillo, Effects of soil characteristics on metribuzin dissipation using clay-gel-based formulations, J. Agric. Food Chem. 57 (2009) 3273-3278.

[34] F. Flores-Céspedes, S. Pérez-García, M Villafranca-Sánchez, M. FernándezPérez, Bentonite and anthracite in alginate-based controlled release formulations to 
1

2

3

4

5

6

7

8

9

10

11

12

13

14

15

16

17

18

19

20

21

22

23

24

25

26

27

28

29

30

31

32

33

34

35

36

37

38

39

40

41

42

43

44

45

46

47

48

49

50

51

52

53

54

55

56

57

58

59

60

61

62

63

64

65

reduce leaching of chloridazon and metribuzin in a calcareous soil. Chemosphere. $192(2013)$ 918-924. 


\section{Figures Caption}

Figure 1. Breakthrough curves of herbicide in soils: Breakthrough curves of metribuzin in sandy-loam soil (a). Breakthrough curves of chloridazon in sandy-loam soil (b). Breakthrough curves of metribuzin in sandy soil (c). Breakthrough curves of chloridazon in sandy soil (d).

Figure 2. Cumulative percentage curves of herbicide recovered in the leachate: Metribuzin in sandy-loam soil (a). Chloridazon in sandy-loam soil (b). Metribuzin in sandy soil (c). Chloridazon in sandy soil (d).

Figure 3. Amount of herbicide (in percentage) recovered in granules, soils and leachates. Metribuzin in sandy-loam soil (a). Chloridazon in sandy-loam soil (b). Metribuzin in sandy soil (c). Chloridazon in sandy soil (d).

Figure 4. Cumulative amount of herbicide recovered in the leachate versus $\mathrm{T}_{50}$ values of herbicide CRFs obtained from water release kinetics. Metribuzin in sandyloam soil (a). Chloridazon in sandy-loam soil (b). Metribuzin in sandy soil (c). Chloridazon in sandy soil (d). 
Table 1.- Characteristics of the soils

\begin{tabular}{lccccc}
\hline Soil sample & $\boldsymbol{p H}$ & O. M. (\%) & Sand (\%) & Silt (\%) & Clay (\%) \\
\hline Soil 1 & 8.70 & 2.27 & 50.36 & 31.28 & 18.36 \\
Soil 2 & 7.80 & 0.70 & 95.40 & 2.00 & 2.60 \\
\hline
\end{tabular}


Table 2.- Characteristics of CRFs containing chloridazon and metribuzin ${ }^{\text {a }}$

\begin{tabular}{|c|c|c|c|c|}
\hline Herbicide & Formulation & $\begin{array}{c}\text { Active } \\
\text { Ingredient (\%) }\end{array}$ & $\begin{array}{c}\text { Encapsulation } \\
\text { Efficiency }^{\mathbf{b}} \\
(\%)\end{array}$ & $T_{50}$ in water $(h)^{c}$ \\
\hline \multirow{4}{*}{ Chloridazon } & CPEL & $14.27(0.36)^{\mathrm{d}}$ & 94.84 & 1.74 \\
\hline & $C P E L+E C_{10}$ & $12.24(0.26)$ & 94.73 & 15.58 \\
\hline & $C P E L+E C_{20}$ & $11.07(0.84)$ & 93.46 & 31.34 \\
\hline & $C P E L+E C_{20}+D B S$ & $10.82(0.47)$ & 93.13 & 65.39 \\
\hline \multirow{4}{*}{ Metribuzin } & MPEL & $11.38(0.13)$ & 85.64 & 1.01 \\
\hline & $M P E L+E C_{10}$ & $10.91(0.52)$ & 98.87 & 11.01 \\
\hline & $M P E L+E C_{20}$ & $9.99(0.26)$ & 98.69 & 20.44 \\
\hline & $M P E L+E C_{20}+D B S$ & $9.24(0.23)$ & 99.41 & 16.94 \\
\hline \multicolumn{5}{|c|}{$\begin{array}{l}\left.{ }^{a} \text { Data previously published (Fernández-Pérez et al., } 2011 ; 2015\right) \\
{ }^{b} \text { Encapsulation efficiency= (Amount of herbicide in dry product/amount of herbicide in formulation processed) } x 100 . \\
{ }^{c^{c}} T_{50} \text { time corresponding to } 50 \% \text { release of herbicide in water } \\
{ }^{d} \text { Values in brackets represent the standard deviation }\end{array}$} \\
\hline \multicolumn{5}{|c|}{$\mathrm{CPEL}+\mathrm{EC}_{10}$ (Chloridazon- polyethylene glycol - lignin - ethylcellulose 10\%) } \\
\hline \multicolumn{5}{|c|}{$\mathrm{CPEL}+\mathrm{EC}_{20}$ (Chloridazon- polyethylene glycol - lignin - ethylcellulose 20\%) } \\
\hline \multicolumn{5}{|c|}{$\mathrm{CPEL}+\mathrm{EC}_{20}+\mathrm{DBS}$ (Chloridazon- polyethylene glycol - lignin - ethylcellulose 20\%-dibutyl sebacate $2.25 \%$ ) } \\
\hline \multicolumn{5}{|c|}{ MPEL+EC 10 (Metribuzin- polyethylene glycol - lignin - ethylcellulose 10\%) } \\
\hline \multicolumn{5}{|c|}{$\mathrm{MPEL}+\mathrm{EC}_{20}$, (Metribuzin - polyethylene glycol - lignin - ethylcellulose 20\%) } \\
\hline $\mathrm{MPEL}+\mathrm{EC}_{20}+\mathrm{DBS}$ & thylene glycol - ligni & llulose $20 \%$ - di & $2.25 \%)$ & \\
\hline
\end{tabular}




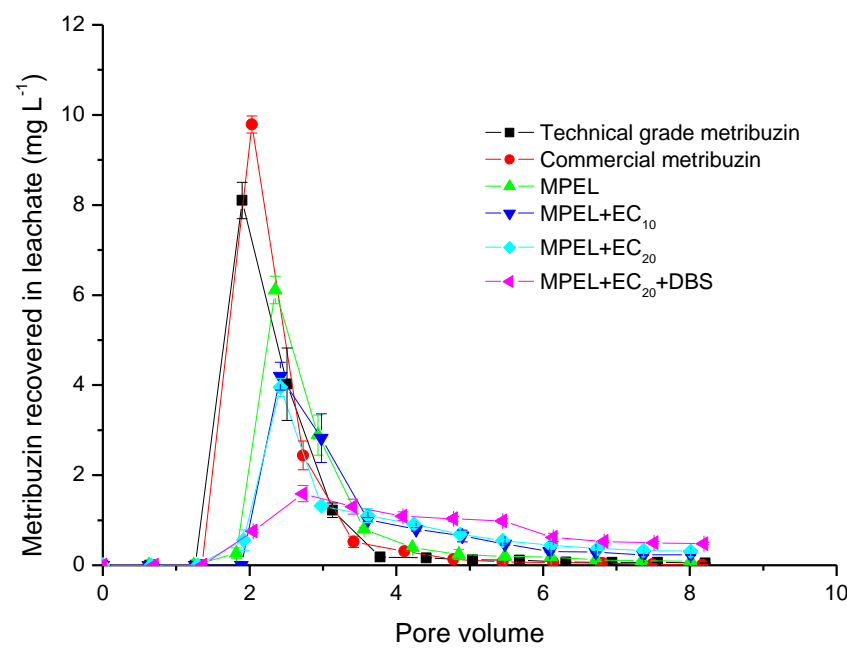

(a)

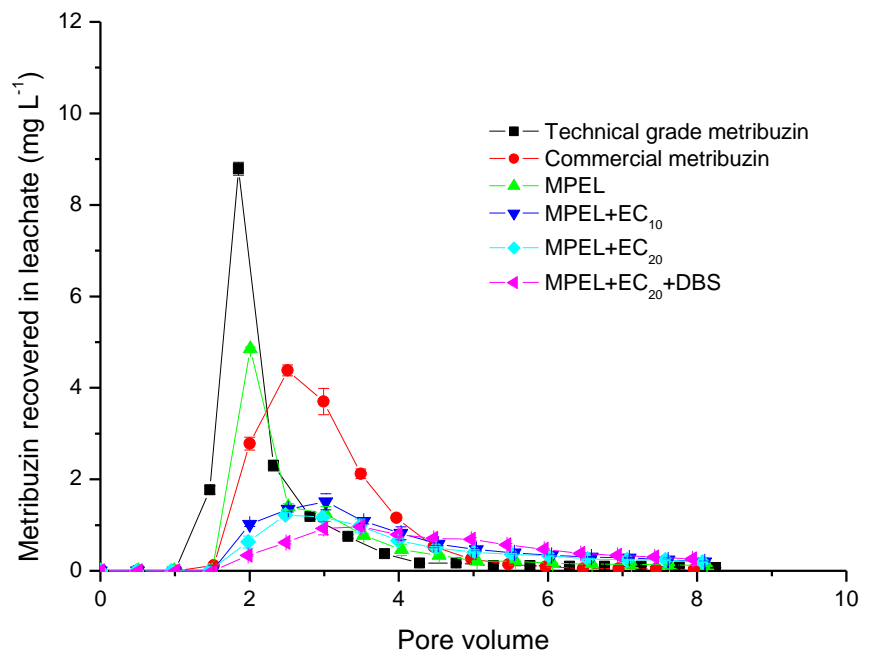

(c)

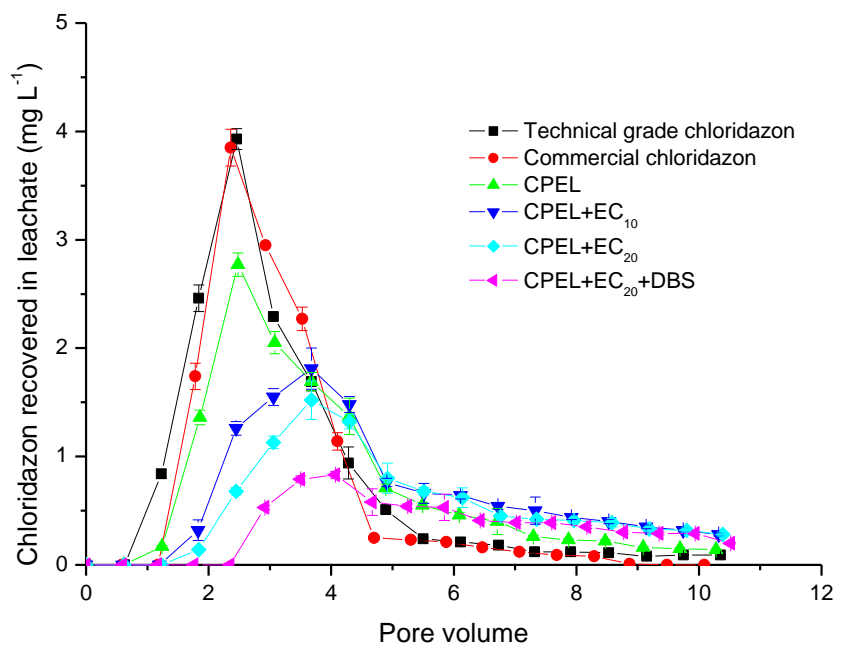

(b)

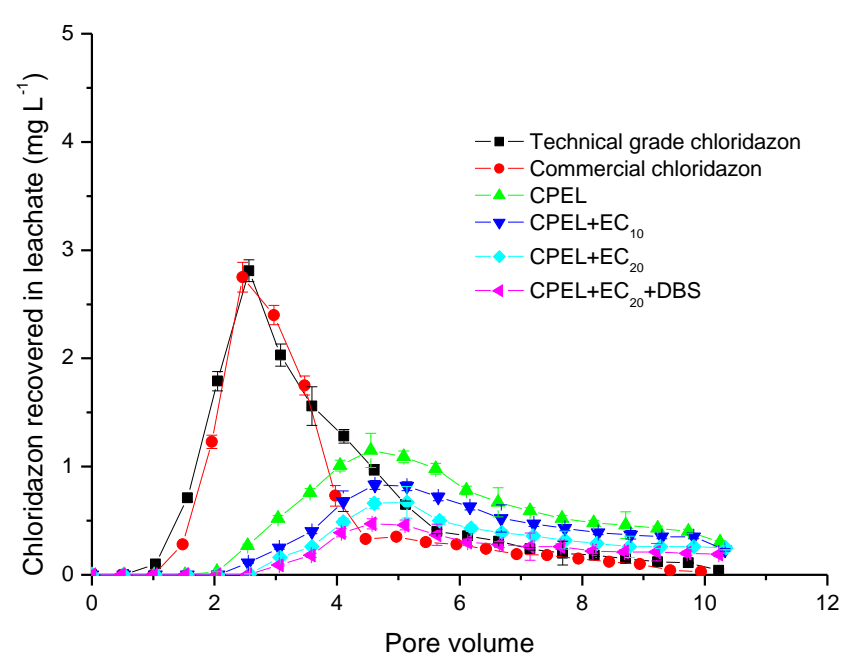

(d)

Figure 1 


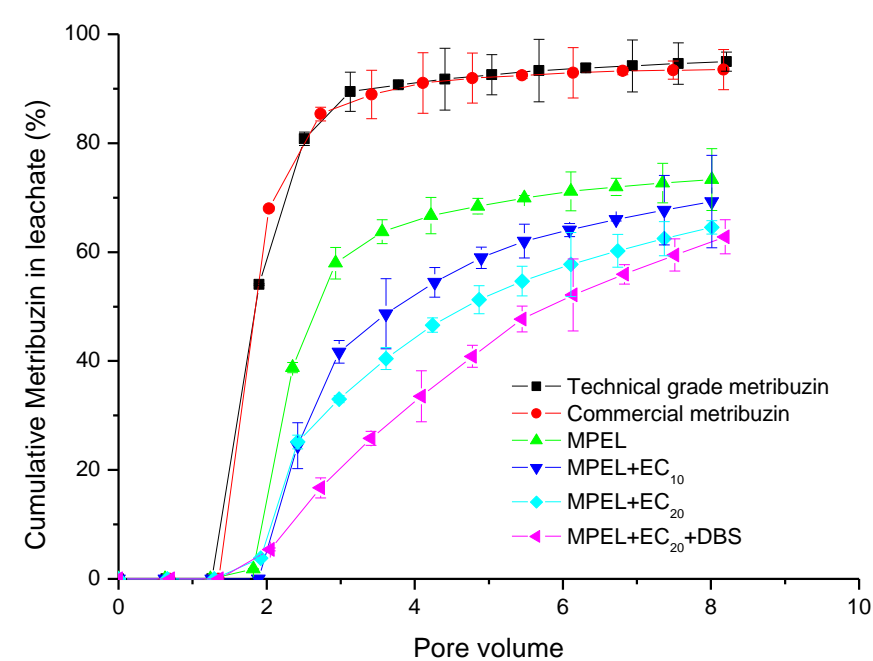

(a)

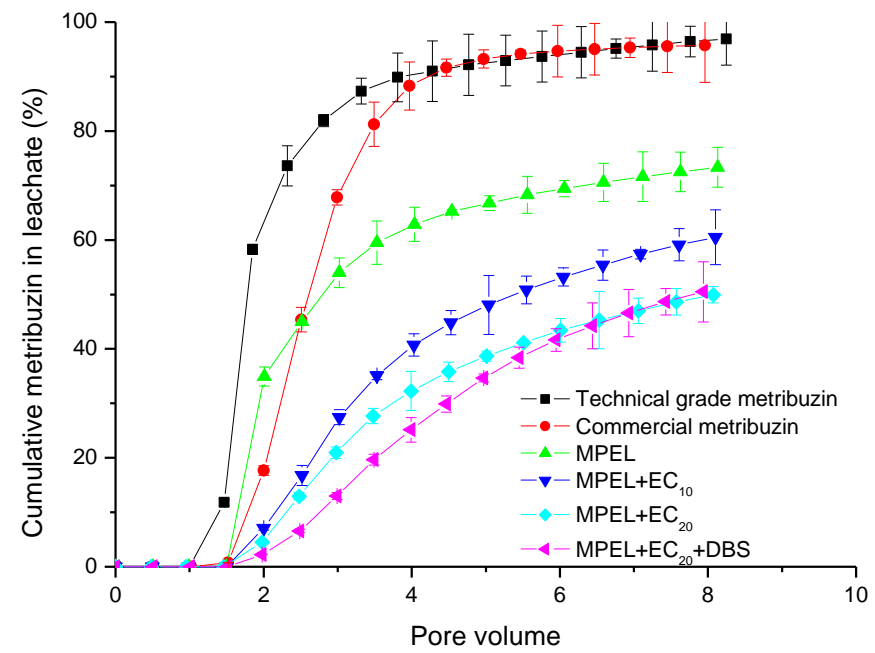

(c)

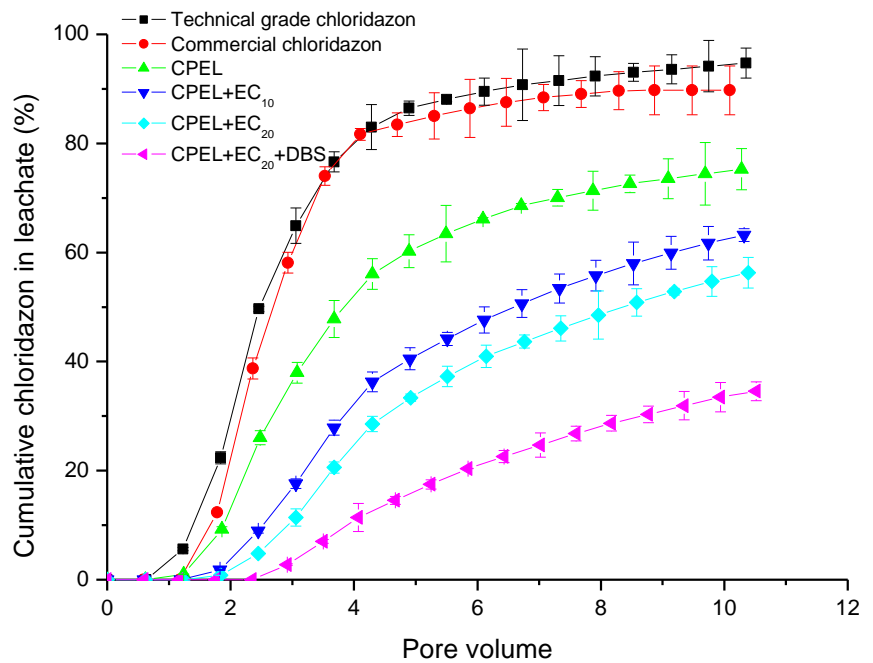

(b)

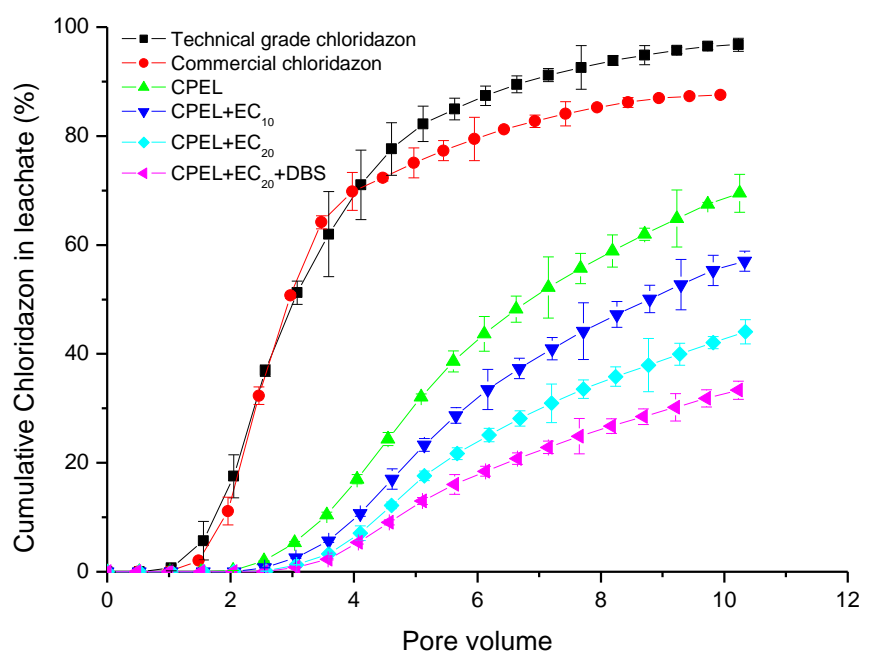

(d)

Figure 2 


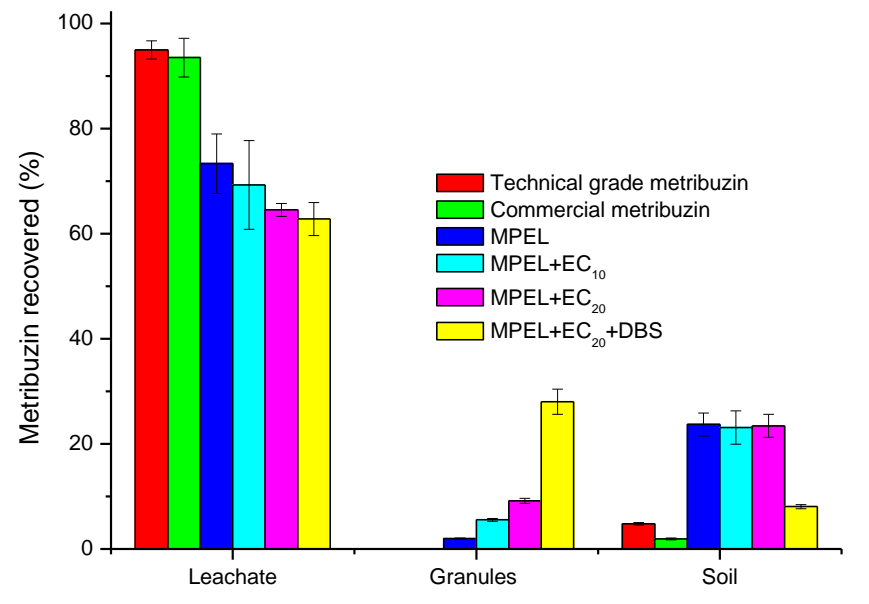

(a)

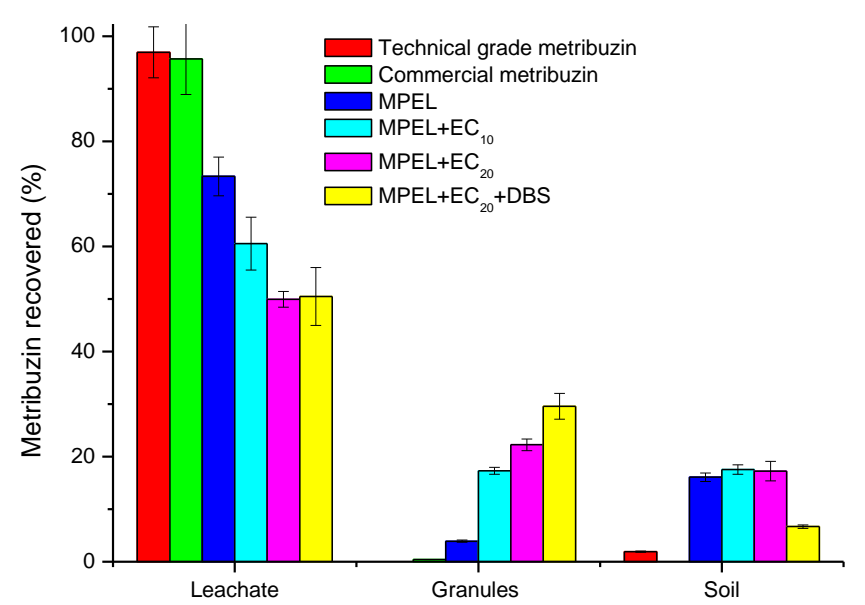

(c)

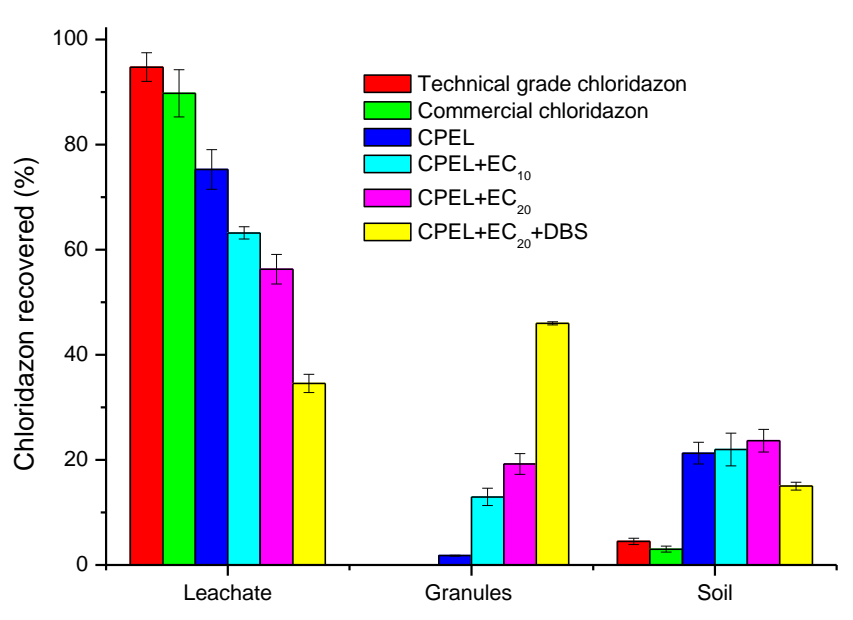

(b)

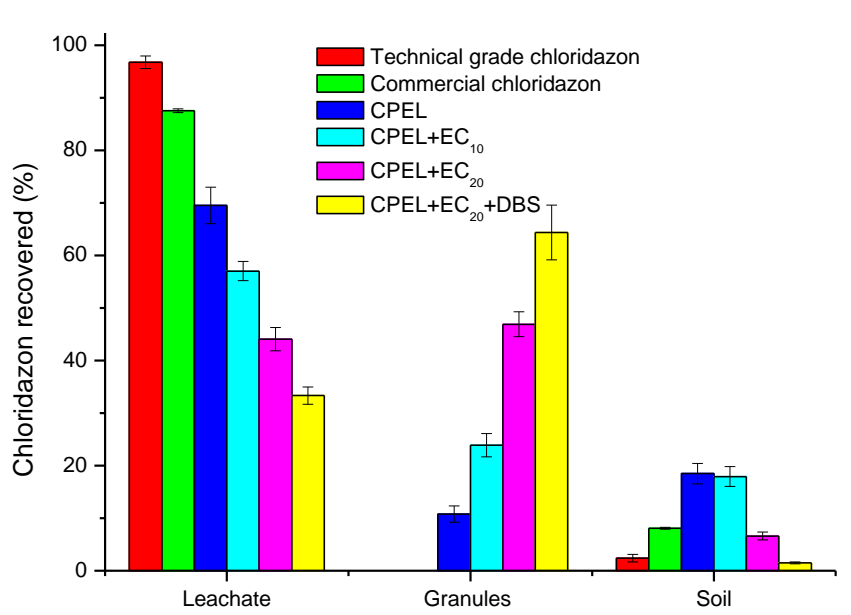

(d)

Figure 3 


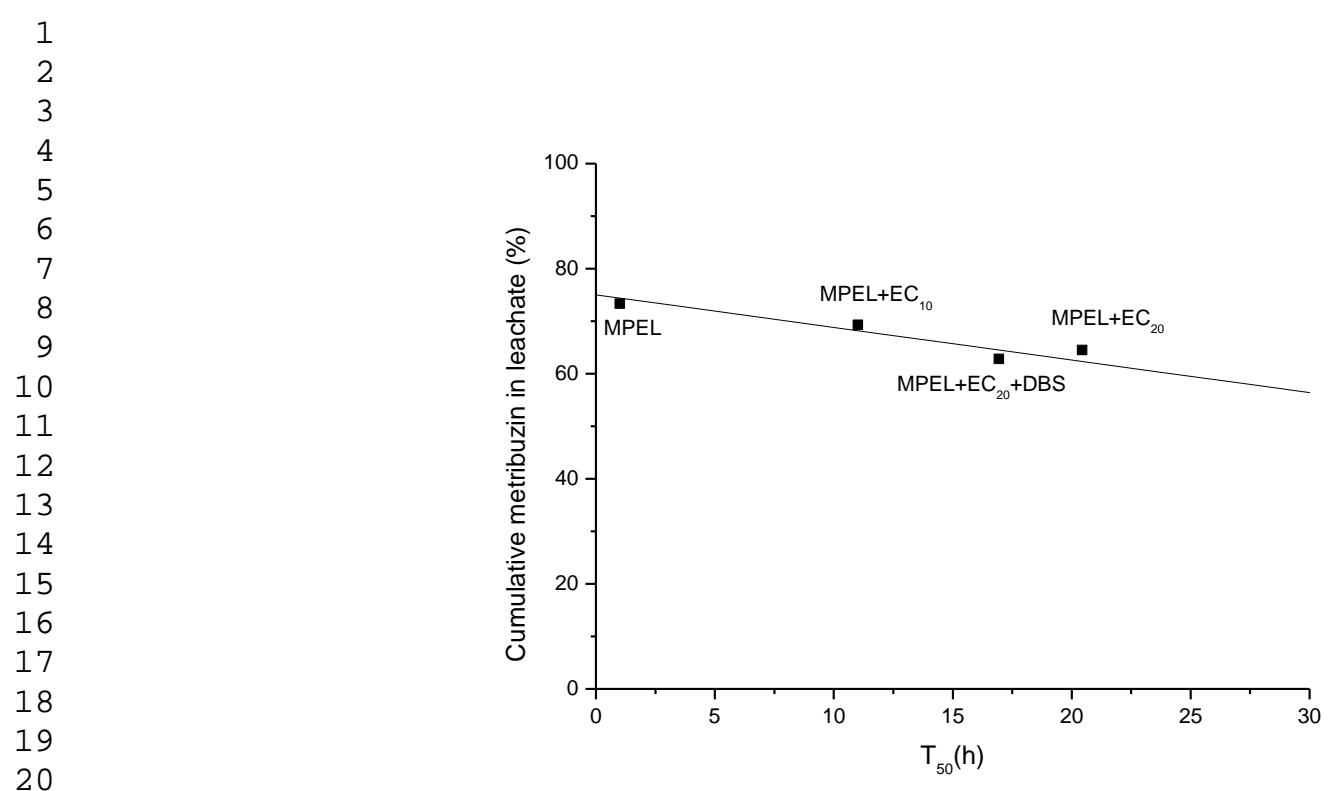

(a)

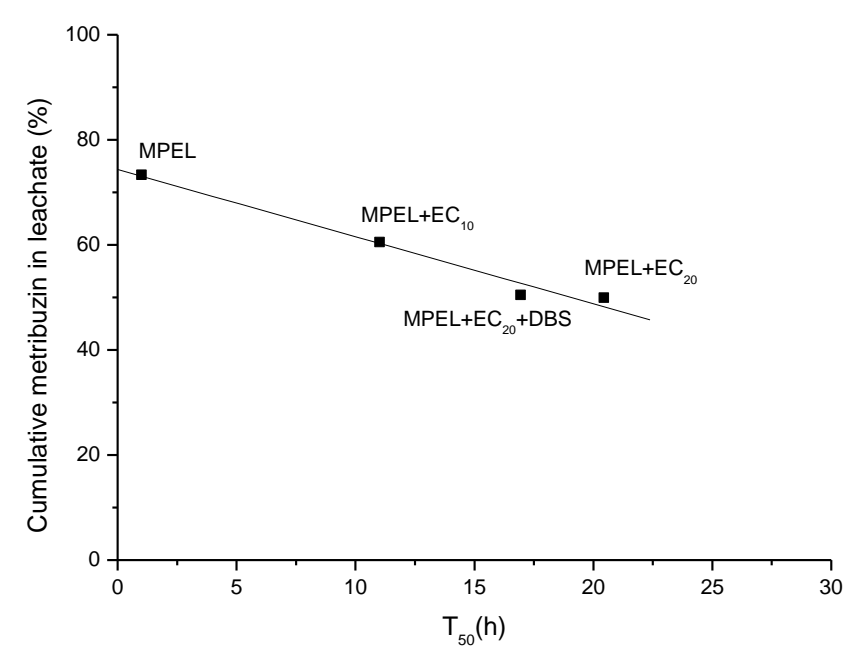

(c)

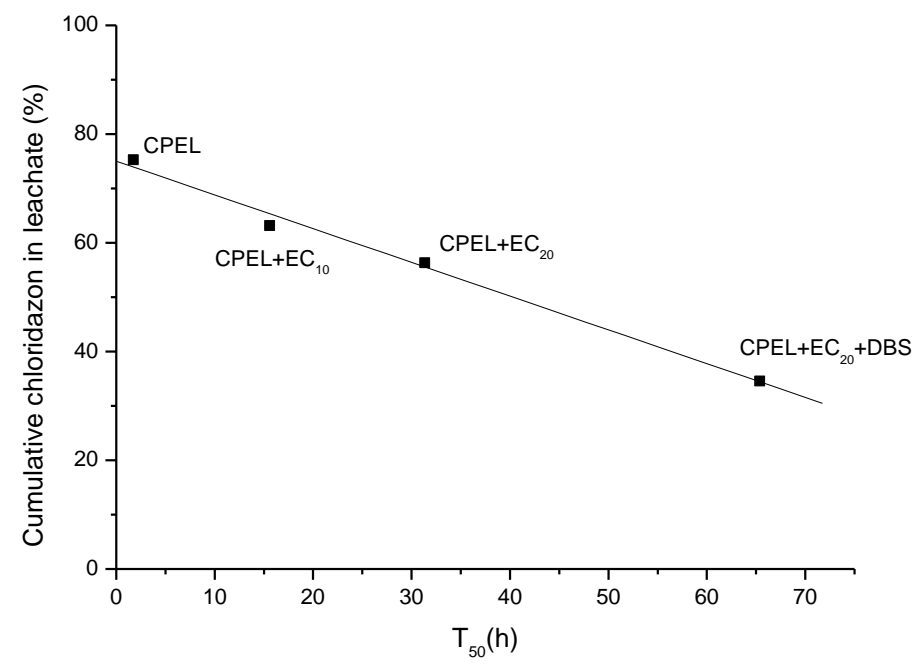

(b)

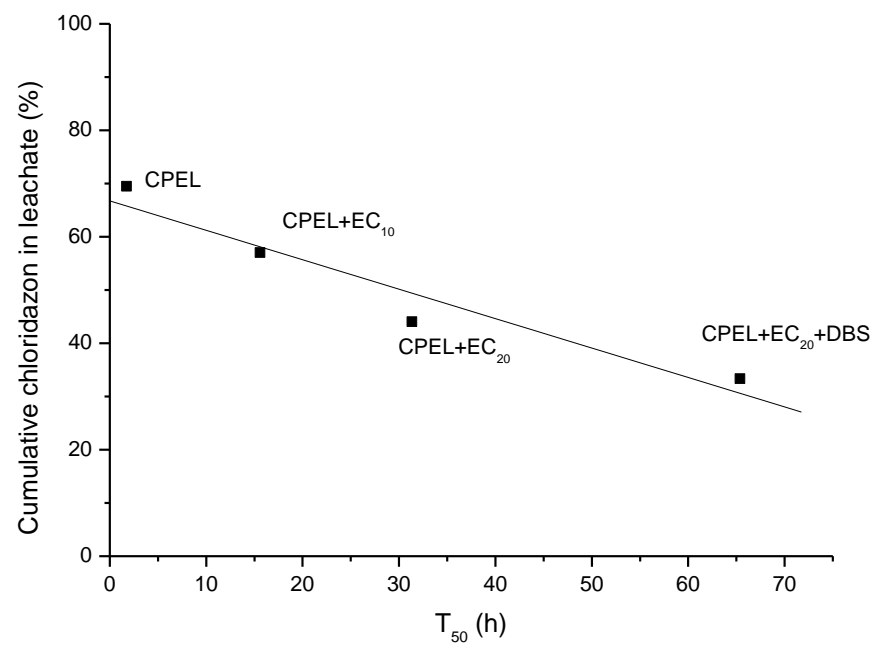

(d)

Figure 4

30 